\title{
Complex Formation of Heavy Metals with 4-(2-Pyridy-lazo)resorcinol Chemically Immobilized on Silica Gel
}

\author{
E. S. Yanovskaya ${ }^{a}$, V. A. Kuzovenko ${ }^{a}$, V. A. Tertykh ${ }^{b}$, and O. Yu. Kichkiruk \\ ${ }^{a}$ Shevchenko National University, Kiev, Vladimirskaya ul. 64, Kiev, 252017 Ukraine \\ ${ }^{b}$ Institute of Surface Chemistry, National Academy of Sciences of Ukraine, Kiev, Ukraine \\ ${ }^{c}$ Franko State University, Zhitomir, Ukraine \\ Received September 11, 2006
}

\begin{abstract}
The complexing properties of modified silica with 4-(2-pyridylazo)resorcinol covalently immobilized by the Mannich reaction are studied with respect to heavy metals. This adsorbent can be used for the preconcentration of heavy metal ions due to its satisfactory kinetic characteristics. The structures of the heavy metal complexes with 4-(2-pyridylazo)resorcinol immobilized on the silica gel surface are studied by ESR and diffuse reflectance spectroscopy.
\end{abstract}

DOI: $10.1134 / \mathrm{S} 107032840708012 \mathrm{X}$

\section{INTRODUCTION}

Inorganic adsorbents with surface-immobilized heterocyclic azo compounds, including 4-(2-pyridylazo)resorcinol (PAR), can be used for extraction, solid-phase concentration, and chromatographic separation of heavy metals [1,2]. These adsorbents [3-5] are characterized by different degrees of washing out of adsorbed PAR, depending on the application conditions. Sorbents with covalently immobilized PAR molecules are much more resistant to washing out due to hydrolytically stable chemical bonds formed with the surface groups $[6,7]$.

The multistage and very labor-consuming process (introduction of nitro groups bound to the benzene ring into the surface layer, their reduction followed by dinitration, and azo coupling with PAR) has been used previously to synthesize supports with a covalently immobilized reactant, giving a sorbent with a low content of grafted complex forming groups and heterogeneous composition of the surface $[6,7]$. The method of onestep aminomethylation (Mannich reaction) using paraformaldehyde as a methylating agent turned out to be promising in this respect. This method has been applied successfully to chemical grafting of oxine, pyridylazonaphthol, and PAR to the silica surfaces [8].

In this work, we present the results of studying the adsorption properties of silica gel with chemically grafted PAR molecules toward toxic metals $\mathrm{Pb}(\mathrm{II})$, $\mathrm{Cd}(\mathrm{II})$, and $\mathrm{Zn}(\mathrm{II})$, as well as toward other metals, namely, $\mathrm{Cu}(\mathrm{II}), \mathrm{Fe}(\mathrm{III}), \mathrm{Co}(\mathrm{II})$, and $\mathrm{Ni}(\mathrm{II})$. 4-(2-Pyridylazo)resorcinol manifests high affinity to these metals, and the adsorbent selectivity can decrease substantially in their presence.

\section{EXPERIMENTAL}

Silica gel with chemically bound PAR was prepared according to a described procedure [8] using the onestep modification of the silica surface by the Mannich reaction involving 3-aminopropyltriethoxysilane and paraformaldehyde via the scheme:

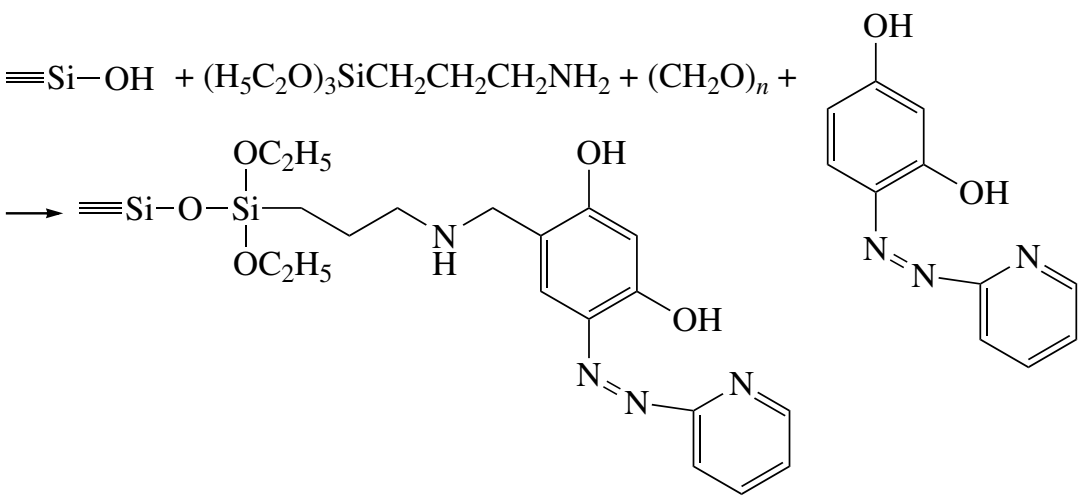


The silica gel with a specific surface area of $256 \mathrm{~m}^{2} / \mathrm{g}$ and a particle diameter of $0.1-0.2 \mathrm{~mm}$ was used as the support. A weighed sample of PAR $(0.43 \mathrm{~g}$, $2 \mathrm{mmol})$ was dissolved in ethanol $(40 \mathrm{ml})$ on heating $\left(60^{\circ} \mathrm{C}\right)$. Then parafomaldehyde $(0.12 \mathrm{~g}, 4 \mathrm{mmol})$, 3 -aminopropyltriethoxysilane $(0.44 \mathrm{ml}, 2 \mathrm{mmol})$, and the support $(50 \mathrm{~g})$ were added. The total volume of alcohol in the reactor was brought to $115 \mathrm{ml}$, and the mixture was kept in a thermostat for $5 \mathrm{~h}$ at $60^{\circ} \mathrm{C}$ with periodical shaking. The obtained modified adsorbent was dried for $2 \mathrm{~h}$ at $120^{\circ} \mathrm{C}$, washed with ethanol 10 times with $70-\mathrm{ml}$ portions and 10 times with $50-\mathrm{ml}$ portions, and then dried at $120^{\circ} \mathrm{C}$ to a constant weight. Spectrophotometry was used to determine the concentration of grafted PAR molecules [9]. A weighed sample of the chemically modified silica gel was dissolved in alkali, and the absorption intensity of the obtained solution was measured at $\lambda=485 \mathrm{~nm}$. Solutions of PAR in alkali were used to plot a calibration curve. The analysis showed that after thorough washing with ethanol, the modified silica surface contained molecules of the grafted reactant in an amount of $0.2 \mathrm{mmol} / \mathrm{g}$.

The initial solutions of metals were prepared by the dissolution of exact weighed samples of the following salts: $\mathrm{Pb}\left(\mathrm{NO}_{3}\right)_{2}, \mathrm{ZnCl}_{2}, \mathrm{Cd}\left(\mathrm{NO}_{3}\right)_{2}, \mathrm{Co}\left(\mathrm{NO}_{3}\right)_{2}, \mathrm{CuSO}_{4}$, $\mathrm{Fe}_{2}\left(\mathrm{SO}_{4}\right)_{3}$, and $\mathrm{Ni}\left(\mathrm{NO}_{3}\right)_{2}$ (all analytical grade). Then the solutions were acidified to avoid hydrolysis. The metal concentrations in the initial solutions were refined titrimetrically using EDTA. The working solutions with the required metal concentration were prepared by diluting the initial solutions with twice distilled water.

Adsorption processes were studied in the static regime with a sorbent weight of $0.1 \mathrm{~g}$ and volumes of the working solutions of $25 \mathrm{~cm}^{3}$. The $\mathrm{pH}$ value of the working solutions was maintained by the addition of buffers prepared from fixanals of standard solutions or ammonia-acetate mixtures and controlled on an I-130.2M.1 ionometer.

The equilibrium concentration of the $\mathrm{Pb}(\mathrm{II}), \mathrm{Cd}(\mathrm{II})$, $\mathrm{Co}(\mathrm{II})$, and $\mathrm{Cu}(\mathrm{II})$ complexes with PAR was determined photometrically on an SF-46 spectrophotometer (quadratic cells with $l=1 \mathrm{~cm}$ ) at $\lambda=520,500,510$, and $490 \mathrm{~nm}$, respectively [10-12]. A procedure with murexide at $\lambda=455 \mathrm{~nm}$ [13] was used for the photometric determination of the $\mathrm{Zn}$ (II) concentration in equilibrium solutions, whereas the reactions with phenanthroline in the presence of a reducing agent [14] and with dimethylglioxime [15] were used for $\mathrm{Fe}$ (III) and $\mathrm{Ni}$ (II), respectively. The amount of metal adsorbed by the chemically modified silica gel was determined from the difference between the ion concentrations in the initial and equilibrium solutions.

Diffuse reflectance (DR) spectra of the complexes on the modified silica gel surface were recorded on a Specord M40 instrument. ESR spectra of the copper(II) complexes were measured on an RE-1306 radio spectrometer at $293 \mathrm{~K}$. The resonance frequency was mea-
Table 1. Absorption bands in the IR spectra of 4-(2-pyridylazo)resorcinol (PAR) and modified silica with grafted PAR

\begin{tabular}{l|l|l}
\hline \multicolumn{2}{c|}{$v \mathrm{~cm}^{-1}$} & \multirow{2}{*}{ Assignment } \\
\cline { 1 - 2 } \multicolumn{1}{c|}{ PAR } & \multicolumn{1}{c}{$\begin{array}{c}\text { modified silica } \\
\text { with PAR }\end{array}$} & \\
\hline 1060 & 1060 & $v(\mathrm{C}-\mathrm{OH})$ \\
1230 & & $\delta(\mathrm{OH})$ \\
$1340,1440,1600$ & $1340,1440,1600$ & $(\mathrm{C}-\mathrm{C})_{\mathrm{ar}}$ \\
1580 & 1580 & $v(\mathrm{C}-\mathrm{N})_{\mathrm{ar}}$ \\
3360 & 3360 & $v(\mathrm{OH})$ \\
\hline
\end{tabular}

sured using a ChZ-54 instrument with a YaZCh-87 frequency converter. Diphenylpicrylhydrazyl $(g=2.0036)$ and $\mathrm{Mn}^{2+}$ ions in the $\mathrm{MgO}$ matrix $(g=2.0015)$ served as standards. Samples in ampules with a diameter of $3 \mathrm{~mm}$ were placed in a resonator. The parameters of the anisotropic spectra were calculated from the position of the lines in parallel orientation of the gfactor $\left(g_{\|}\right)$with an accuracy of 0.005 or estimated from the lines in perpendicular orientation of the $g$ factor $\left(g_{\perp}\right)$ according to [16]. IR spectra of samples were recorded on a Nexus-470 FTIR spectrophotometer in a region of $400-4000 \mathrm{~cm}^{-1}$.

\section{RESULTS AND DISCUSSION}

To confirm PAR immobilization on the surface layer of the silica gel, we compared the IR spectra of the synthesized sorbent and of the initial reactant (Table 1). The IR spectrum of the modified adsorbent in regions $<1200$ and $3000-3800 \mathrm{~cm}^{-1}$ exhibits intense absorption bands of the framework and hydrate layer of silica, which hamper identification of some functional groups of immobilized molecules. At the same time, the band of the stretching vibrations of the $\mathrm{OH}$ groups of the PAR molecules at $3360 \mathrm{~cm}^{-1}$ can be identified rather reliably in the spectrum of the adsorbent. The region of $1000-1600 \mathrm{~cm}^{-1}$ in the IR spectra is most informative to confirm the presence of PAR in the modifying silica layer. This region contains absorption bands at $1580 \mathrm{~cm}^{-1}$ corresponding to skeletal vibrations of the $\mathrm{C}-\mathrm{N}$ bonds at $1600 \mathrm{~cm}^{-1}$ (the most intense band) and bands at 1340 and $1440 \mathrm{~cm}^{-1}$ caused by vibrations of the aromatic rings.

The studies of the dependence of the degree of extraction of the metals on the acidity of the solution (Table 2) showed that the silica gel with chemically immobilized PAR extracts quantitatively the $\mathrm{Pb}^{2+}$, $\mathrm{Cd}^{2+}$, and $\mathrm{Ni}^{2+}$ ions in neutral and weakly alkaline media. The sorption capacity of the obtained sorbent toward these metals is rather high and makes it possible to extract them quantitatively from aqueous solutions in a wide concentration interval $(0.1-100 \mu \mathrm{g} / \mathrm{ml})$. In this case, the $\mathrm{Zn}^{2+}, \mathrm{Co}^{2+}, \mathrm{Cu}^{2+}$, and $\mathrm{Fe}^{3+}$ ions are partially 
Table 2. Dependence of the degree of extraction $(\%)$ of the metal ions on the silica gel with chemically grafted $\mathrm{PAR}$ on $\mathrm{pH}$ of the solution*

\begin{tabular}{c|c|c|c|c|c|c|c}
\hline \multirow{2}{*}{ Metal ion } & \multicolumn{7}{|c}{$\mathrm{pH}$ of solution } \\
\cline { 2 - 7 } & 1.0 & 1.7 & 4.0 & 6.8 & 7.0 & 8.0 & 9.2 \\
\hline $\mathrm{Zn}^{2+}$ & 55.5 & 84.6 & 78.8 & 92.9 & 87.5 & 89.3 & 71.3 \\
$\mathrm{Cd}^{2+}$ & 0 & 0 & 0 & 92.0 & 99.9 & 92.0 & 92.4 \\
$\mathrm{~Pb}^{2+}$ & 0 & 0 & 21.2 & 99.9 & 99.9 & 99.9 & 95.6 \\
$\mathrm{Cu}^{2+}$ & 36.4 & 69.7 & 76.6 & 85.1 & 83.0 & 86.4 & 82.3 \\
$\mathrm{Fe}^{3+}$ & 0 & 92.6 & 93.0 & 97.5 & 88.8 & 68.8 & 67.6 \\
$\mathrm{Co}^{2+}$ & 0 & 0 & 72.5 & 99.9 & 84.8 & 84.8 & 84.8 \\
$\mathrm{Ni}^{2+}$ & 20.0 & 50.0 & 75.0 & 99.9 & 99.9 & 99.9 & 99.9 \\
\hline
\end{tabular}

* Experimental conditions: static regime, weight of the adsorbent $0.1 \mathrm{~g}$, weight of the metal in the initial solution $100 \mu \mathrm{g}$, adsorption time $24 \mathrm{~h}$.

extracted. In acidic media at $\mathrm{pH} 1-4$, the synthesized adsorbent quantitatively extracts none of these metals.

The results of studying the kinetics of adsorption of the metals in question in the static regime in a neutral medium at $\mathrm{pH}$ 6.8-7.0 show that the silica gel with chemically immobilized PAR extracts quantitatively the $\mathrm{Pb}^{2+}, \mathrm{Cd}^{2+}$, and $\mathrm{Co}^{2+}$ ions for 2-5 min under these conditions. The maximally possible (higher than $83 \%$ ) degree of extraction of the $\mathrm{Cu}^{2+}$ ions is attained within the same time. The achieved degree of adsorption of the

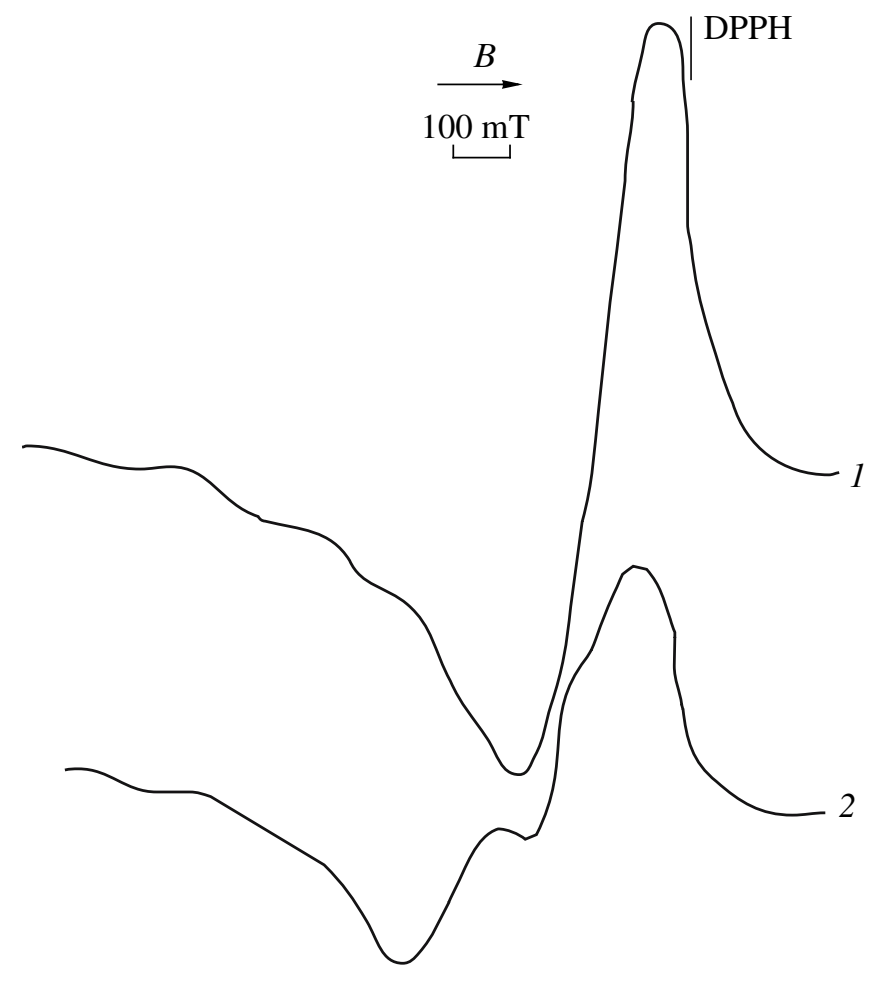

Fig. 1. ESR spectra of the $\mathrm{Cu}(\mathrm{II})$ complexes with PAR chemically immobilized on the silica gel surface after adsorption of (1) 0.013 and (2) $0.062 \mathrm{mmol} / \mathrm{g}$ copper.
$\mathrm{Fe}^{3+}$ and $\mathrm{Zn}^{2+}$ ions is $\sim 89$ and $95 \%$, respectively (10-min contact). The maximum degree of extraction of the $\mathrm{Ni}^{2+}$ ions is achieved for $1 \mathrm{~h}$.

Thus, the silica adsorbent with covalently immobilized PAR synthesized by one-step aminomethylation reaction is characterized by satisfactory rate of adsorption of toxic metal ions and can be used for their extraction from solutions in the dynamic regime.

The ESR spectra of the complexes formed on the silica gel surface with covalently immobilized PAR molecules during $\mathrm{Cu}^{2+}$ ion adsorption are characterized by the asymmetric shape, anisotropy, and hyperfine structure of the signal $g_{\|}$(Fig. 1, Table 3). The values of the parallel component of the $g$ factor and hyperfine splitting constant $\left(\boldsymbol{A}_{\|}\right)$calculated from the ESR spectra of sample 1 (in which the concentration of adsorbed copper is several times lower than the concentration of grafted PAR molecules) are characteristic of octahedral oxygen complexes with the $\mathrm{Cu}\left[\mathrm{O}_{4} \mathrm{O}_{2}\right]$ coordination unit (adducts of copper bis(chelates) with strong axial coordination to positions 5 and 6 [17]) or octahedral complexes similar to those formed in crystalline hydrate $\mathrm{CuSO}_{4} \cdot 5 \mathrm{H}_{2} \mathrm{O}[18,19]$.

These complexes can be formed by copper(II) coordination to the oxygen atoms of two hydroxyl groups of two PAR molecules and two water molecules or two hydroxyl groups of one 4-(2-pyridylazo)resorcinol molecule and four water molecules.

For a low degree of coverage of the PAR-modified silica gel with copper(II), the complexes with the coordination mode different from those known for solutions prevail. This is indirectly confirmed by the fact that at low concentrations, copper is sorbed nonquantitatively and more poorer than the $\mathrm{Pb}^{2+}$ and $\mathrm{Cd}^{2+}$ ions (Table 2), although the stability constant of the copper complexes with this reactant in solution is much higher than those for the latter [9].

A comparison of the ESR spectrum of sample 2 in which the amount of adsorbed copper exceeds the concentration of the grafted PAR molecules with the spec- 
Table 3. Parameters of the ESR spectra of the complexes of $\mathrm{Cu}^{2+}$ ions with PAR covalently bound with the silica surface

\begin{tabular}{c|c|c|c|c}
\hline \multirow{2}{*}{ Sample } & \multirow{2}{*}{$\begin{array}{c}\text { Amount adsorbed of } \mathrm{Cu}^{2+} \text { ions, } \\
\mathrm{mmol} / \mathrm{g}\end{array}$} & $g_{\|}$ & $g_{\perp}$ & $A_{\|} \times 10^{-4}, \mathrm{~cm}^{-1}$ \\
\cline { 2 - 4 } & 0.013 & 2.380 & 2.039 & 179 \\
2 & 0.062 & 2.310 & 2.028 & 173 \\
\hline
\end{tabular}

trum of sample 1 shows that an increase in the adsorbed copper concentration decreases the $g_{\|}$and $A_{\|}$values (Table 3). The calculated parameters of the spectrum of sample 2 (concentration of the coordinated metal is $0.062 \mathrm{mmol} / \mathrm{g}$ ) correspond to those for the complexes of four-coordinate copper(II) with the $\left[\mathrm{N}_{2} \mathrm{O}_{2}\right]$ coordination unit [20-22], as it usually occurs for the complex formation of the PAR molecules with the $\mathrm{Cu}^{2+}$ ions in solutions.

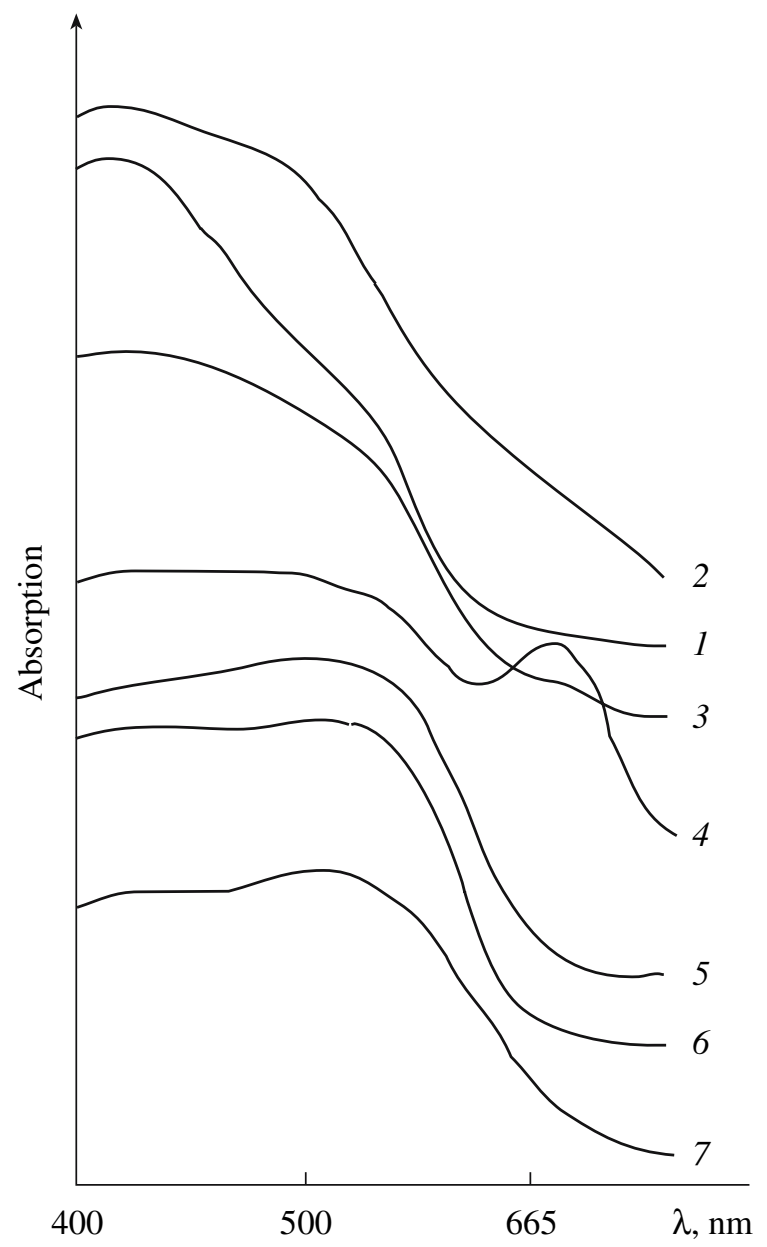

Fig. 2. Diffuse reflectance spectra of (1) PAR, (2) silica gel with chemically grafted PAR, and (3-7) surface complexes of PAR with the $\mathrm{Cu}^{2+}, \mathrm{Cd}^{2+}, \mathrm{Fe}^{3+}, \mathrm{Pb}^{2+}$, and $\mathrm{Zn}^{2+}$ ions, respectively.
The DR spectra of the metal complexes with the PAR molecules chemically modified on the silica surface (Fig. 2) are characterized by absorption bands in the visible region at 525, 510, 700, 520 and $700,500 \mathrm{~nm}$ for $\mathrm{Cu}(\mathrm{II}), \mathrm{Cd}(\mathrm{II}), \mathrm{Fe}(\mathrm{III}), \mathrm{Pb}(\mathrm{II})$, and $\mathrm{Zn}(\mathrm{II})$, respectively. These data indicate that the coordination mode of the $\mathrm{Cd}^{2+}$ and $\mathrm{Pb}^{2+}$ ions with the PAR molecules chemically grafted to the silica gel surface by the onestep aminomethylation reaction is similar to that for complex formation in solutions. Also note that, according to published data [23], the complexes with the $\mathrm{Zn}^{2+}$ ions formed on the surface of the PAR-containing sorbent obtained by the sol-gel method are also characterized by a band at $500 \mathrm{~nm}$. The DR spectra of the $\mathrm{Cu}(\mathrm{II})$ complexes with PAR with different copper contents in the samples are similar.

Thus, the silica gel with covalently immobilized PAR synthesized by one-step aminomethylation through the Mannich reaction extracts quantitatively at $\mathrm{pH}$ 6.8-7.0 particularly toxic metals such as $\mathrm{Pb}(\mathrm{II})$, $\mathrm{Cd}(\mathrm{II})$, and $\mathrm{Ni}(\mathrm{II})$ and sorbs partially the $\mathrm{Zn}^{2+}, \mathrm{Cu}^{2+}$, $\mathrm{Fe}^{3+}$, and $\mathrm{Co}^{2+}$ ions due to the formation of surface complexes. The data on the DR spectra showed that the coordination mode of PAR chemically grafted to the silica surface by the $\mathrm{Cd}^{2+}$ and $\mathrm{Pb}^{2+}$ ions is similar to that for the interaction of the components in solutions.

The ESR study of the structures of the $\mathrm{Cu}^{2+}$ complexes with PAR immobilized on silica indicates that the octahedral oxygen complexes $\mathrm{Cu}\left[\mathrm{O}_{4} \mathrm{O}_{2}\right]$ predominate at low coverages of the surface with the metal, whereas the complexes with the $\left[\mathrm{N}_{2} \mathrm{O}_{2}\right]$ coordination unit prevail when the content of the adsorbed copper increases.

The synthesized chemically modified silica is characterized by rather good ability to adsorb metal ions due to the pronounced complexing properties of the surface groups. This makes the obtained adsorbent promising for use in the processes of solid-phase concentration of heavy metals during analyses of different natural objects.

\section{REFERENCES}

1. Basova, E.M., Bol'shova, T.A., Shpigun, O.A., and Ivanov, V.M., Zh. Anal. Khim., 1993, vol. 48, no. 7, p. 1094.

2. Ivanov, V.M., Zh. Anal. Khim., 1991, vol. 46, no. 4, p. 645 .

3. Sato, K., Monden, M., and Goto, T., Bunseki Kagaku, 1999, vol. 48, no. 2, p. 261. 
4. Tange, H., Yasuda, M., and Goto, T., Bunseki Kagaku, 2000, vol. 49, no. 4, p. 239.

5. Ivanov, V.M., Ershova, N.I, and Figurovskaya, V.N., Zh. Anal. Khim., 2002, vol. 57, no. 10, p. 1052 [J. Anal. Chem. (Engl. Transl.), vol. 57, no. 10, p. 890].

6. Lieser, K., Breitwieser, E., and Burda, P., Mikrochim. Acta (Wien), 1978, no. 1, p. 363.

7. Forster, M., Lieser, K., and Fresenius, Z., Anal. Chem., 1981, vol. 309, no. 5, p. 355.

8. Tertykh, V.A., Yanishpolskii, V.V., and Panova, O.Yu., J. Therm. Anal. Calorim., 2000, vol. 62, no. 2, p. 545.

9. Pilipenko, A.T., Pilipenko, L.A., and Zubenko, A.I., Organicheskie reaktivy $v$ neorganicheskom analize (Organic Reagents in Inorganic Analysis), Kiev: Naukova Dumka, 1994, p. 54.

10. Marczenko, Z., Kolorymetryczne Oznaczanie Pierwiastkow, Warszawa: Wysdawnictwa Naukowo-Techniczne, 1968.

11. Shcherbov, D.P. and Matveets, M.A., Analiticheskaya khimiya kadmiya (Analytical Chemistry of Cadmium), Moscow: Nauka, 1973.

12. Pyatnitskii, I.V., Analiticheskaya Khimiya Elementov: Kobal't (Analytical Chemistry of Elements: Cobalt), Moscow: Nauka, 1965.

13. Zhivopistsev, V.P. and Selezneva, E.A., Analiticheskaya khimiya tsinka (Analytical Chemistry of Zinc), Moscow: Nauka, 1975.
14. Charlo, G., Les Methodes de la chimie analytique: Analyse quantitative minerale, Paris: Masson, 1961.

15. Peshkova, V.M. and Savostina, V.M., Analiticheskaya khimiya nikelya (Analytical Chemistry of Nickel), Moscow: Nauka, 1966.

16. Lipatova, T.E. and Nizel'skii, Yu.N., Uspekhi khimii poliuretanov (The Advances in Polyurethane Chemistry), Kiev: Naukova Dumka, 1972.

17. Shklyaev, A.A. and Nizel'skii, Yu.N., Kataliticheskie svoistva $\beta$-diketonatov metallov (Catalytic Properties of Metal $\beta$-Diketonates), Kiev: Naukova Dumka, 1983.

18. Kivelson, D. and Neiman, R.J., Chem. Phys., 1961, vol. 35, no. 1, p. 149.

19. Al'tshuler, S.A. and Kozyrev, B.M., Elektronnyi Paramagnitnyi Rezonans Soedinenii Promezhutochnykh Grupp (Electron Paramagnetic Resonance of Compounds of Intermediate Groups), Moscow: Nauka, 1972.

20. Shklyaev, A.A., Anufrienko, V.F., and Ogorodnikov, V.D., Zh. Strukt. Khim., 1973, vol. 14, no. 6, p. 994.

21. Marov, I.N. and Kostromina, N.A., YaMR i EPR v Khimii Koordinatsionnykh Soedinenii (NMR and EPR in the Chemistry of Coordination Compounds), Moscow: Nauka, 1979.

22. Tikhomirova, N.N. and Zamaraev, K.I., Zh. Strukt. Khim., 1963, vol. 4, no. 2, p. 224.

23. Jeronimo, P.C.A., Araujo, A.N., Conceicao, M., and Montenegro, B.S.M., Sensors and Actuators. B: Chemical, 2004, vol. 103, p. 169. 